\title{
The Impact of Family Cohesion and Flexibility on University Students' Identity: The Case of Shiraz Branch, Islamic Azad University
}

\author{
Hassan Rahgozar \\ Department of Economic and Management, Shiraz Azad University Branch \\ Islamic Azad University, Shiraz, Iran \\ E-mail: rahgozarhassan@yahoo.com
}

Soqra Yousefi

Master student in consultant, Science and Research Branch, Islamic Azad University, Kerman, Iran

Ali Mohammadi

Master student in consultant, Science and Research Branch, Islamic Azad University, Kerman, Iran

Pegah Piran

Faculty of Psychology and Educational Sciences, Marvdasht Branch

Islamic Azad University, Marvdasht, Iran

Received: August 15, 2011

Accepted: August 28, $2011 \quad$ Published: February 1, 2012

doi:10.5539/ass.v8n2p95

URL: http://dx.doi.org/10.5539/ass.v8n2p95

\begin{abstract}
This research aims to study the effect Family's flexibility and cohesion on shaping the identity of students at Shiraz Branch, Islamic Azad University. The Causal Comparative method is applied to conduct the research and the statistical sample included 375 students, selected randomly from Azad university of Shiraz. Measuring tools in this study include: 1). The Ego Identity Process Questionnaire (EIPQ) 2). Positive Flexibility Questionnaire and 3). Family Cohesion Questionnaire.
\end{abstract}

The result indicated that family flexibility and cohesion affect identity of students positively, especially in terms of the two dimensions of exploration and commitment.

Keywords: Family cohesion, Family flexibility, Commitment, Exploration, Identity, Students

\section{Introduction}

Identity is "a subjective sense as well as an observable quality of personal sameness and continuity, paired with some belief in the sameness and continuity of some shared world image. As a quality of unself-conscious living, this can be gloriously obvious in a young person who has found himself as he has found his communality. In him we see emerge a unique unification of what is irreversibly given--that is, body type and temperament, giftedness and vulnerability, infantile models and acquired ideals--with the open choices provided in available roles, occupational possibilities, values offered, mentors met, friendships made, and first sexual encounters" (Erikson, 1970).

Many psychologists have insisted on the Adolescence period to be a crisis; but, Erikson believes that teenagers or young adults will gain moderated psychological balance if s/he comes to know him/herself in the right time by learning to interact properly with the society through the experiences s/he has had. But, if s/he is lost in identity and is uncertain of her individual identity, s/he will not have psychological balance and will be facing identity crisis. Thus, a youth's growth toward perfection is based upon the solution to identity crisis (Salehi Amiri, Kavousy \& Tohidy Ardahaey, 2009). 
Teenage youth thrive on their sense of independence and the development of selfhood. How they identify themselves within a larger community, then, proves interesting because they are at a crossroads between the development of self and their involvement in a community. Family relations is an appropriate background from which to identify exactly how a teenager's sense of agency and selfhood appears in language because, as it allows them to view and analyze the world around them, it is an integral part of their developmental process (Note 1). This study is dealing with the role of family cohesion and flexibility on identification of students' identity, considering the viewpoints of some well-known theorists in terms of dimensions of exploration and commitment.

\section{Family and Cultural Identity}

Since the creation of a family relies not on "the genetic connection, but the day-today living together and nurturing of common human values ("Review" 1994, 42), how important is maintaining cultural identity in this increasingly interdependent world? Elizabeth Bartholet cannot find any evidence that "the challenge of establishing a satisfactory ethnic and cultural identity causes any harm to the international adoptee" (Bartholet, 1993, 98). She believes that this argument against international adoption does not involve genuine concerns over the risks to children. Rather, she finds that children are being sacrificed for the sake of group pride and honor. Bartholet states, "The current tendency to glorify group identity and to emphasize the importance of ethnic and cultural roots combines with nationalism to make international adoption newly suspect in this country as well as in the world at large" (Bartholet 1993, 100).

On the other hand, ideally, each culture has so much to offer every other culture that the more individuals can integrate a multi-cultural perspective into their lives, the more comprehensively and meaningfully people can live their lives. Exposing peoples (especially children) to various cultures may enhance their perspective on life and the world. Although the children receive benefits from resourceful parents and the foreign country (in this case, the United States), substituting one culture for another may deprive these children of a wealth of opportunities as well as of a part of their own identity.

Given all these considerations, is it even possible for parents to manifest their adopted child's culture into their lives given the fact that it is foreign to them? (Note 2)

\section{Research Goal}

\subsection{Main Goal}

The main goal of this research is to study the impact of family cohesion and flexibility on formation of university students' identity.

\subsection{Side Objectives}

1). Studying the impact of family cohesion and flexibility on formation of exploration in university students

2). Studying the impact of family cohesion and flexibility on formation of commitment in university students

\section{Research Questions}

1). How much does the family cohesion and flexibility affect university student' identity and forming their exploration?

2). How much does the family cohesion and flexibility affect university student' identity and forming their commitment?

\section{Research Theoretical Framework}

\subsection{Erikson's Theory}

Erikson was a Neo-Freudian. He has been described as an "ego psychologist" studying the stages of development, spanning the entire lifespan. Erikson's greatest innovation was to postulate not five stages of development, as Sigmund Freud had done with his psychosexual stages, but eight, and then later added a ninth stage in his book "The Life Cycle Completed." Erik Erikson believed that every human being goes through a certain number of stages to reach his or her full development, theorizing eight stages that a human being goes through from birth to death (Schickendanz, 2001). Erikson elaborated Freud's genital stage into adolescence, and added three stages of adulthood. His widow Joan Serson Erikson elaborated on his model before her death, adding a ninth stage (old age) to it, taking into consideration the increasing life expectancy in Western cultures. Erikson is also credited with being one of the originators of Ego psychology, which stressed the role of the ego as being more than a servant of the id. According to Erikson, the environment in which a child lived was crucial to providing growth, adjustment, a source of self awareness and identity. Each of Erikson's stages of psychosocial development are 
marked by a conflict, for which successful resolution will result in a favorable outcome, for example, trust vs. mistrust, and by an important event that this conflict resolves itself around, for example, the meaning of one's life.

Favorable outcomes of each stage are sometimes known as "virtues", a term used, in the context of Eriksonian work, as it is applied to medicines, meaning "potencies." Erikson's research suggests that each individual must learn how to hold both extremes of each specific life-stage challenge in tension with one another, not rejecting one end of the tension or the other. Only when both extremes in a life-stage challenge are understood and accepted as both required and useful, can the optimal virtue for that stage surface. Thus, 'trust' and 'mis-trust' must both be understood and accepted, in order for realistic 'hope' to emerge as a viable solution at the first stage. Similarly, 'integrity' and 'despair' must both be understood and embraced, in order for actionable 'wisdom' to emerge as a viable solution at the last stage.

The Erikson life-stage virtues, in the order of the stages in which they may be acquired, are:

1) hope - Basic Trust vs. Mistrust - Infant stage / 0-1 year. Does the child believe its caregivers to be reliable?

2) will - Autonomy vs. Shame and Doubt - Toddler stage / 1-3 years. Child needs to learn to explore the world. Bad if the parent is too smothering or completely neglectful.

3) purpose - Initiative vs. Guilt - Preschool / 3-6 years - Can the child plan or do things on his own, such as dress him or herself. If "guilty" about making his or her own choices, the child will not function well. Erikson has a positive outlook on this stage, saying that most guilt is quickly compensated by a sense of accomplishment.

4) competence - Industry vs. Inferiority - School-age / 6-11. Child comparing self worth to others (such as in a classroom environment). Child can recognize major disparities in personal abilities relative to other children. Erikson places some emphasis on the teacher, who should ensure that children do not feel inferior.

5) fidelity - Identity vs. Role Confusion - Adolescent / 12 years till mid twenties. Questioning of self. Who am I, how do I fit in? Where am I going in life? Erikson believes that if the parents allow the child to explore, they will conclude their own identity. However, if the parents continually push him/her to conform to their views, the teen will face identity confusion.

6) love (in intimate relationships, work and family) - Intimacy vs. Isolation - Young adult / mid twenties till early forties. Who do I want to be with or date, what am I going to do with my life? Will I settle down? This stage has begun to last longer as young adults choose to stay in school and not settle.

7) caring - Generativity vs. Stagnation - early forties till mid sixties / starts as the Mid-life crisis. Measure accomplishments/failures. Am I satisfied or not? The need to assist the younger generation. Stagnation is the feeling of not having done anything to help the next generation.

8) wisdom - Ego Integrity vs. Despair - old age / from mid sixties. Some handle death well. Some can be bitter, unhappy, and/or dissatisfied with what they have accomplished or failed to accomplish within their lifetime. They reflect on the past, and either conclude at satisfaction or despair.

On ego identity versus Role Confusion, ego identity enables each person to have a sense of individuality, or as Erikson would say, "Ego identity, then, in its subjective aspect, is the awareness of the fact that there is a self-sameness and continuity to the ego's synthesizing methods and a continuity of one's meaning for others" (1963). Role Confusion, however, is, according to Barbara Engler in her book Personality Theories (2006), "The inability to conceive of oneself as a productive member of one's own society" (158). This inability to conceive of oneself as a productive member is a great danger; it can occur during adolescence when looking for an occupation (Note 3).

\subsection{Olson's Theory}

In recent years, family therapists have sought to establish the credibility of their therapeutic approach by building the evidence base for models of practice. One such family therapy model - Olson's Circumplex Model - is supported by over 1,200 studies conducted over the last 30 years (Olson, 2011), making it highly attractive to psychologists working with families under stress.

The Olson Circumplex Model (Olson, 2000) conceptualises flexibility, cohesion and communication skills as three central variables that define family interactions. Based on a conceptual clustering of many concepts 
designed to describe family and couple dynamics, the model "is specifically designed for clinical assessment, treatment planning and research on outcome effectiveness of marital and family therapy" (Olson, 2000, p.144).

The Circumplex Model suggests that "balanced levels of cohesion and flexibility are most conducive to healthy family functioning. Conversely, unbalanced levels of cohesion and flexibility (very low or very high levels) are associated with problematic family functioning" (Olson, 2011, p.65).

Olson's model addresses flexibility through examining the amount of change that is possible in leadership, role relationships and family rules. Both stability and change are necessary in healthy family and couple relationships, and the ability to allow change when it is needed distinguishes functional from dysfunctional families.

Too little flexibility leads to rigidity, with the family or couple relationship unable to shift or evolve in response to change, whether it arises internally through individual members' development or is imposed by the environment. Too much flexibility results in chaos, with family members unable to create shared agreements that govern their actions and inter-relationships, providing no firm base on which to stand. In between these two extremes lies the balanced options of flexible or structured families, where the balance between rigidity and chaos is negotiated from a strong base of shared understanding of rules and roles within the relationship.

The level of emotional bonding between family members is measured in the Circumplex Model through the degree of cohesion - the extent and nature of connections, boundaries and shared interests within the family. Cohesion refers to the balance between family members' independence and their togetherness (see boxed information). Once again, both appropriate levels of connection to, and independence from, family are important for maintaining healthy relationships.

Too much closeness results in enmeshment - families exhibit extreme amounts of emotional closeness and may be dependent on, and reactive to, one another. High levels of family loyalty and consensus are required and there is little tolerance for private space or relationships outside the family. Too much separateness causes disengagement, where families exhibit little emotional closeness, instead remaining focussed on individual experiences and activities. There is limited commitment to family interests, and members are often unable to turn to one another for emotional or practical support or assistance. The balance is found for separated or connected families, where a balance between individual and group interests supports optimal family functioning.

The level of emotional bonding between family members is measured in the Circumplex Model through the degree of cohesion - the extent and nature of connections, boundaries and shared interests within the family. Cohesion refers to the balance between family members' independence and their togetherness (see boxed information). Once again, both appropriate levels of connection to, and independence from, family are important for maintaining healthy relationships.

Too much closeness results in enmeshment - families exhibit extreme amounts of emotional closeness and may be dependent on, and reactive to, one another. High levels of family loyalty and consensus are required and there is little tolerance for private space or relationships outside the family. Too much separateness causes disengagement, where families exhibit little emotional closeness, instead remaining focussed on individual experiences and activities. There is limited commitment to family interests, and members are often unable to turn to one another for emotional or practical support or assistance. The balance is found for separated or connected families, where a balance between individual and group interests supports optimal family functioning.

Olson views flexibility and cohesion as two dimensions on a grid (see Figure 1), so that families can be, for example, flexibly connected, or structurally separated, or chaotically enmeshed, or rigidly disengaged. Families and couples which are characterised by more balanced characteristics tend to be more functional over the developmental cycle, and tend to have better communications skills and habits (white boxes in Figure 1). Families and couples who possess more unbalanced tendencies find it challenging to deal with the pressures caused by changes in working arrangements, illness and injury, infidelity, challenging child behaviours, or the intersecting developmental arcs of different family members (black boxes in Figure 1). They tend to have poor communications skills. Families with a mixture of balanced and unbalanced styles (grey boxes in Figure 1) will find it challenging to deal with pressures and changes, but have a stronger foundation on which to base a move to a more balanced mode of interaction, especially if they can also develop their communications skills.

The model is particularly useful when working with families or couples who are entrenched in their positions to explain that the situation doesn't have to be black or white, all or none. It demonstrates clearly how incremental change can be helpful, provides clues as to how individual actions can bring results, and visibly illustrates the 'shades of grey' that lie between the simple considerations of 'balanced' and 'unbalanced'. Interventions which 
improve communications skills can support families to move closer to optimal flexibility and cohesion, and changes in one dimension can have flow on effects to other dimensions.

The Circumplex Model operates on the fundamental assumption that families naturally progress through cycles of change in response to altered environmental demands and the evolving needs of family members. This is termed 'second order change', which involves a change in the rules which govern the system and effectively creates a 'new' family better suited to its conditions. Functional families understand change - that a couple's relationship will alter once a baby arrives, that it's not appropriate to parent a 16-year-old in the same way you parented a 6-year-old, that when adult children leave home the degree of closeness with parents will alter - and adjust their interactions to meet the required levels of flexibility and cohesion. Balanced families flexibly transform from one arrangement to another in times of stress and as the life cycle unfolds. Conversely, unbalanced families tend to remain condemned to their dysfunctional patterns, which further increase the pressures on the system.

Having the ability to understand and respond to needs for increased or decreased closeness or flexibility in a relationship is a protective mechanism. Once presenting symptoms are addressed, the family is empowered with the tools to respond functionally to future pressures, environmental changes and the developmental trajectories of its members (Note 4).

\subsection{Marcia's Theory}

Marcia is perhaps best known for his extensive research and writings on psychological development, with specific attention focused on adolescent psychosocial development and lifespan identity development. Erik H. Erikson had suggested that the normative conflict occurring in adolescence is the opposition between identity achievement and identity confusion. Marcia elaborated on Erikson's proposal in a citation classic (Marcia, 1966) by suggesting this stage consists neither of identity resolution nor identity confusion as Erikson claimed, but is better understood as the extent to which one has both explored and committed to an identity in a variety of life domains including politics, occupation, religion, intimate relationships, friendships, and gender roles. 'Two crucial areas in which the adolescent must make such commitments are ideology and occupation' (Marcia, 1973).

His theory of identity achievement states that there are two distinct parts contributing to the achievement of adolescent identity: a time of choosing or crisis, and a commitment. He defined a crisis as a time of upheaval where old values or choices are being reexamined and new alternatives are explored - 'times during adolescence when the individual seems to be actively involved in choosing among alternative occupations and beliefs' (Marcia 1973). Both exploration and commitment are the two processes that contribute to differences in outcome during an Identity crisis. That is, whether or not (the extent to which) one explores identity alternatives and whether or not one makes a commitment to chosen alternatives (Note 5).

Once a crisis has become, 'a likely progression would be from diffusion through moratorium to identity achievement'. The latter is thus the status of individuals who have typically experienced a crisis, undergone identity explorations and made commitments. Marcia found some evidence to support his 'theoretical description of Ss who have achieved an identity as having developed an internal, as opposed to external, locus of self-definition' (Marcia, 1973).

\subsubsection{The four identity statuses according to Marcia}

Marcia developed the Identity Status Interview, a method of semi-structured interview for identity research that investigates an individual's extent of exploration and commitment across different life areas. Evaluating the material provided in this interview by using a scoring manual developed by Marcia and colleagues yields four possible outcomes, or Identity Statuses, of psychological identity development: Foreclosure, Identity Diffusion, Moratorium, and Identity Achievement. The four identity statuses are shown in table 1.

\subsubsection{Foreclosure}

'The foreclosure status is when a commitment is made without exploring alternatives. Often these commitments are based on parental ideas and beliefs that are accepted without question' (Identity Development, Vol 4). As Marcia put it, ' the individual about to become a Methodist, Republican farmer like his Methodist, Republican farmer father, with little or no thought in the matter, certainly cannot be said to have "achieved" an identity, in spite of his commitment.

Adolescents may foreclose on the handed-down identity willingly or under pressure. The case of "negative-identity" occurs when adolescents adopt an identity in direct opposition to a prescribed identity. Foreclosures' 'endorsement of authoritarian values...is consistent with the description of them as becoming their 
parents' alter egos'. Marcia stressed that 'once the foreclosure position is left behind (i.e. a crisis has been experienced), it is no longer an option' (Marcia, 1973).

\subsubsection{Identity Diffusion}

'Some adolescents become overwhelmed by the task of identity development and neither explore nor make commitments...may become socially isolated and withdrawn' (Identity Development, Vol 4): Identity diffusion. 'Identity Diffusion is generally considered the least mature and least complex status' (Cote and Levine, 2002) of the four identity statuses. Identity Diffusion is the status of individuals who have neither explored nor made commitments across life-defining areas. They may or may not have experienced a crisis, with some Diffusions reporting having little interest in such matters and others reporting repeated indecision.

Marcia suggested that those with identity diffusion 'do not experience much anxiety because there is little in which they are invested. As they begin to care more...they move to the moratorium status, or they become so disturbed that they are diagnosed schizophrenic' (Marcia, 1973). Others indicate that 'in the most extreme cases of role diffusion, adolescents may adopt a negative identity' (Brich, 1997).

\subsubsection{Moratorium}

Identity moratorium is the status of individuals who are in the midst of a crisis but whose commitments are either absent or are only vaguely defined. 'The moratorium status is characterized by the active exploration of alternatives' (Identity Development, Vol 4). Marcia noted that 'moratoriums...report experiencing more anxiety than do Ss in any other status...The world for them is not, currently, a highly predictable place; they are vitally engaged in a struggle to make it so' (Marcia, 1997).

Nevertheless over time a tendency has been observed for longer periods to be spent in the status, as 'Children of the Sixties...granted themselves a long moratorium on commitments...'Provisional Adulthood' (Sheehy, 1996).

\subsubsection{Identity achievement}

Once a crisis has become, 'a likely progression would be from diffusion through moratorium to identity achievement'. The latter is thus the status of individuals who have typically experienced a crisis, undergone identity explorations and made commitments. Marcia found some evidence to support his 'theoretical description of Ss who have achieved an identity as having developed an internal, as opposed to external, locus of self-definition' (Marcia, 1973).

\subsubsection{Applicability and criticism}

While Marcia primarily focused on the late adolescent years, his theory is applicable in later adulthood, when identity crises may reoccur. One study, exploring correlations between the identity statuses of Marcia's model and social behaviors, focused on young adults ranging in age from 19 to 35 (Hardy and Kisling, 2006). People's identity status is not specifically limited to an age group. Individuals may explore elements tied to their identity throughout life, such as faith, ideology, and occupational preference to name a few (Identity Development, $\mathrm{Vol}$ 4).

Using Marcia's semi-structured interview approach enables research to be flexibly adapted to different cultures. There has been a good deal of cross-cultural validation of the Identity Statuses.

Critical research has suggested however that '(a) The four statuses do not operate in a developmental sequence...(b) conscious exploration is not required for and often does not occur in identity achievement; and (c) numerous studies conducted in support of the statuses focus less on developmental issues and more on classification issues (Cote 2006; Miller, 2009).

\section{Research Conceptual Model}

Figure 2 shows the relationship between studied variables and dimensions of identity in this research.

\subsection{Research Method}

The research method in this study is causal comparative method.

\subsection{Statistical Population and Sample}

The statistical population in this research included all students (18155 people) at Shiraz Branch, Islamic Azad University. The sample size was 376 people based on Morgan Table.

\subsection{Measurement Tools}

Measuring tools in this study included: 
1). The Ego Identity Process Questionnaire (EIPQ)

2). Positive Flexibility Questionnaire and

3). Family Cohesion Questionnaire

\section{Research Findings}

According to table 2, the score average of cohesion and commitment among female students were higher than among male students and the score average of flexibility and exploration among male students were higher than among female ones.

\subsection{Research $1^{\text {st }}$ question}

How much does the family cohesion and flexibility affect university student' identity and forming their exploration?

In order to answer the above question, the method of multiple regression was applied simultaneously.

According to table 3 , variables of family cohesion and flexibility affect the dimension of exploration positively and can be predicted as positive

\subsection{Research $2^{\text {nd }}$ question}

How much does the family cohesion and flexibility affect university student' identity and forming their commitment?

In order to answer the above question, the method of multiple regression was applied simultaneously.

According to table 4 , variables of family cohesion and flexibility affect the dimension of commitment positively and can be predicted as positive

\section{Conclusion}

This research aimed to study the effect of family cohesion and flexibility on identity and its two dimensions of exploration and commitment of students at Shiraz Branch, Islamic Azad University. The results from the research showed that the score average of cohesion and commitment among female students were higher than among male students and the score average of flexibility and exploration among male students were higher than among female ones. Also, it was proved that variables of family cohesion and flexibility affect the dimension of exploration positively and can be predicted as positive and variables of family cohesion and flexibility affect the dimension of commitment positively and can be predicted as positive.

Following results were also obtained from the research findings:

1). Mail students gained a higher score in dimension of exploration and in order to reach a high level of exploration, they preferred a high level of flexibility in the family, where female students preferred lower level of flexibility to reach a high level of exploration.

2). Female students gained a higher score in dimension of commitment. Bothe male and female students preferred a high level of family cohesion (and a moderate level of flexibility) to reach a high level of commitment.

3). Junior male and female students are higher in exploration dimension in comparison with senior ones and the level of exploration among junior male and female students in comparison with senior ones is not much affected by family cohesion and flexibility.

4). Senior male and female students are higher in commitment dimension in comparison with junior ones and the level of commitment among senior male and female students in comparison with junior ones is not much affected by family cohesion and flexibility.

\section{References}

Bartholet, Elizabeth. (1993). International Adoption: Current Status and Future Prospects. The Future of Children, Vol. 3, Spring: 89-103. http://dx.doi.org/10.2307/1602404

Birch, A. (1997). Developmental Psychology. London, p. 206.

Cote J. E. \& Levine C. G. (2002). Identity Formation, Agency and Culture. Lawrence Erlbaum Associates, Publishers, p. 19.

Erikson, E.H. (1970). Reflections on the dissent of contemporary youth. International Journal of Psychoanalysis, 51, 11-22. 
Hardy, S. A. \& Kisling, J. W. (2006). Identity statuses and prosocial behaviors in young adulthood: A brief report. Identity: An International Journal of Theory and Research, 6(4), 363-369.

Identity Development - Aspects of Identity. Child Development Reference, Vol. 4. [Online] Available: http://social.jrank.org/pages/322/Identity-Development.html

Marcia, J. E. (1966). Development and validation of ego identity status. Journal of Personality and Social Psychology, 3, pp. 551-558. http://dx.doi.org/10.1037/h0023281

Marcia, J. E. (1973). Ego-Identity Status, in Michael Argyle. Social Encounters, Penguin.

Miller T. W. (2009). Handbook of Stressful Transitions Across the Lifespan. Child \& School Psychology, p. 93.

Olson, D.H. (2000). Circumplex Model of Marital and Family Systems. Journal of Family Therapy, 22, 144-167. http://dx.doi.org/10.1111/1467-6427.00144

Olson, D. (2011). FACES IV and the Circumplex Model: Validation study. Journal of Marital and Family Therapy, 37(1), 64-80. http://dx.doi.org/10.1111/j.1752-0606.2009.00175.x

Review. Sojourner. (1994). 19, no. 9. May, 41-42.

Salehi Amiri S. R., Kavousy E. \& Tohidy Ardahaey F. (2009). Assessing Social-Cultural Factors Affecting Identity Crisis of the Youth in Iran. Social Science Research Network (SSRN). [Online] Available: http://papers.ssrn.com/sol3/papers.cfm?abstract_id=1392649

Schickendanz, Judith A. (2001). Chapter 1 Theories of Child Development and Methods of Studying Children. Understanding Children and Adolescents (4th ed.). Allyn and Bacon, pp.12-13.

Sheehy, G. (1996). New Passages. London, p. 43, p. 10.

[Online] Available: http://english.cmu.edu/inquiry/fly-naomi.pdf

[Online] Available: http://www.adoptionpolicy.org/pdf/cultural_id.pdf

[Online] Available: http://en.wikipedia.org/wiki/Erik_Erikson

[Online] Available: http://www.psychology.org.au/publications/inpsych/2011/february/sanders/

[Online] Available: http://en.wikipedia.org/wiki/James_Marcia

\section{Notes}

Note 1. http://english.cmu.edu/inquiry/fly-naomi.pdf

Note 2. http://www.adoptionpolicy.org/pdf/cultural_id.pdf

Note 3. http://en.wikipedia.org/wiki/Erik_Erikson

Note 4. http://www.psychology.org.au/publications/inpsych/2011/february/sanders/

Note 5. http://en.wikipedia.org/wiki/James_Marcia

Table 1 . The four identity statuses in Marcia's theory

\begin{tabular}{|c|c|c|c|}
\hline & \multicolumn{3}{|c|}{ Exploration } \\
\hline$\Xi$ & & Law & High \\
\hline$\Xi$ & High & Foreclosure & Identity achievemen \\
\hline$U$ & Law & Moratorium & Identity Diffusion \\
\hline
\end{tabular}

Table 2. Average and standard deviation of identity; family cohesion and flexibility

\begin{tabular}{|c|c|c|c|c|c|}
\hline \multirow[t]{3}{*}{ Variables } & 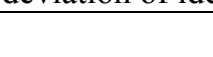 & \multicolumn{4}{|l|}{ Sex } \\
\hline & & \multicolumn{2}{|l|}{ Male } & \multicolumn{2}{|l|}{ Female } \\
\hline & & SD & Average & SD & Average \\
\hline \multirow[t]{2}{*}{ Identity } & Exploration & 3.23 & 68 & 2.21 & 65 \\
\hline & Commitment & 3.25 & 54 & 2.45 & 60 \\
\hline \multirow{2}{*}{$\begin{array}{l}\text { Family } \\
\text { functions }\end{array}$} & Cohesion & 23.21 & 98.56 & 12.65 & 102.21 \\
\hline & Flexibility & 11.86 & 70.02 & 15.23 & 61.23 \\
\hline
\end{tabular}


Table 3. The extent to predict the dimension of exploration (from identity dimensions) in terms of variables of family cohesion and flexibility

\begin{tabular}{|l|l|l|l|l|l|l|}
\hline $\begin{array}{l}\text { Predicted } \\
\text { variables }\end{array}$ & $\mathbf{P}$ & $\mathbf{F}$ & $\mathbf{R}$ & $\mathbf{P}<$ & $\mathbf{t}$ & $\mathbf{B}$ \\
\cline { 1 - 5 } $\begin{array}{l}\text { Family } \\
\text { cohesion }\end{array}$ & 0.001 & 124.11 & 0.61 & 0.01 & 15.02 & 0.61 \\
\cline { 1 - 5 } $\begin{array}{l}\text { Family } \\
\text { flexibility }\end{array}$ & & & & 0.01 & 7.23 & 0.41 \\
\cline { 4 - 7 }
\end{tabular}

Table 4. The extent to predict the dimension of commitment (from identity dimensions) in terms of variables of family cohesion and flexibility

\begin{tabular}{|l|l|l|l|l|l|l|}
\hline $\begin{array}{l}\text { Predicted } \\
\text { variables }\end{array}$ & $\mathbf{P}$ & $\mathbf{F}$ & $\mathbf{R}$ & $\mathbf{P}<$ & $\mathbf{t}$ & $\mathbf{B}$ \\
\cline { 1 - 5 } $\begin{array}{l}\text { Family } \\
\text { cohesion }\end{array}$ & 0.01 & 96.12 & 0.52 & 0.001 & 11.02 & 0.41 \\
\cline { 1 - 5 } $\begin{array}{l}\text { Family } \\
\text { flexibility }\end{array}$ & & & & 0.01 & 9.23 & 0.37 \\
\cline { 5 - 7 }
\end{tabular}

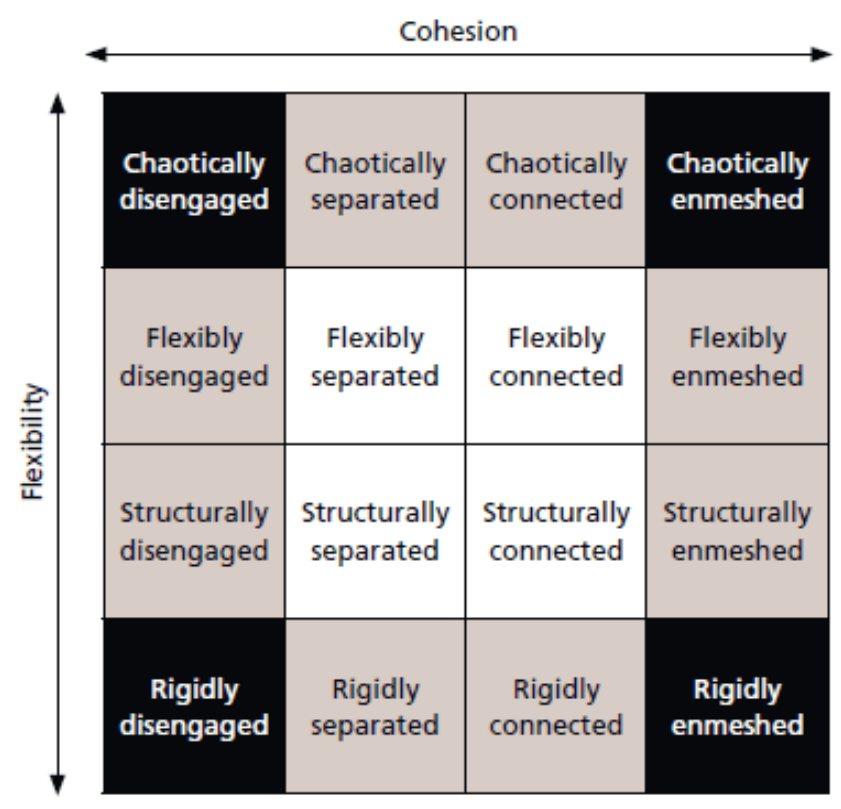

Figure 1. The Circumplex Model (after Olson, 2000)

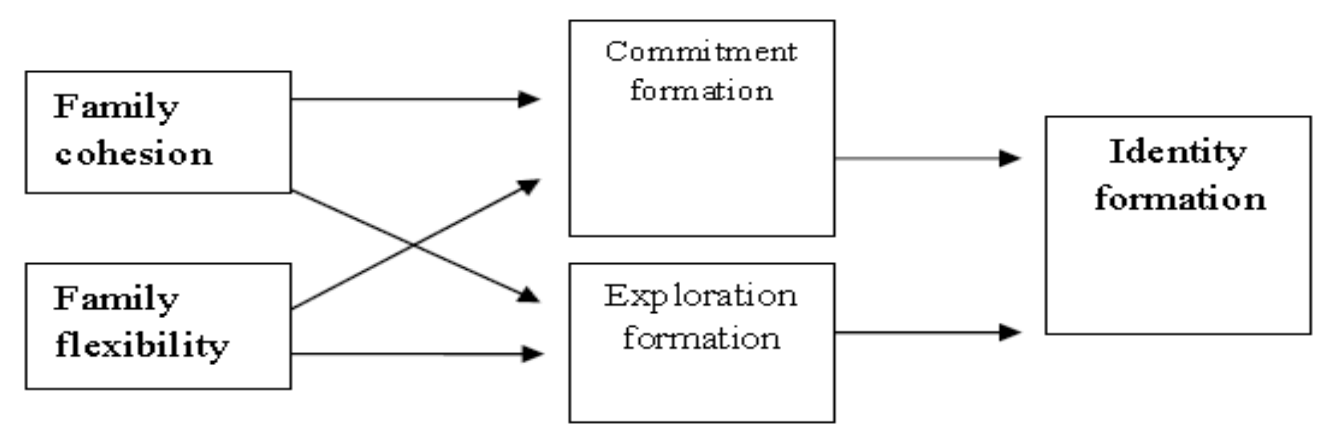

Figure 2. Research framework and conceptual model 